Viti i XII ${ }^{\text {te }}$ i Botimit, Nr.1-2,

Dhjetor 2020

\title{
IDETË E JASHAR REXHEPAGIQIT PËR DEMOKRATIZIMIN E ARSIMIT
}

\author{
NË KOSOVË.
}

\section{Hajri Mandri*}

\author{
*Departamenti i Edukimit dhe Anglishtes, Fakuleteti i Shkencave Shoqërore, Albanian \\ University, Tiranë
}

Adresë kontakti : $\quad$ hajrimandri@gmail.com

\section{Përmbledhje}

Jashar Rexhepagiq mbetet një ndër pedagogët e shquar të Kosovës me përkushtim gjysëmshekullor. Edhe tani kur veprimtaria virtuale e ka shndërruar shoqërinë kosovare në një shkollë të madhe të një shoqërie që mëson, idetë pedagogjike të Rexhepagiqit tingëllojnë aktuale. Rexhepagiq la pas një pasuri të vyer në fushën e pedagogjisë. Ai mbetet një edukator i madh idealist që projektoi veten në të ardhmen. Demokracia autentike, konkrete dhe praktike në arsim, nuk konsiderohen fjalë boshe, por ide, që janë të realizueshme, reale dhe ardhshmëri e bashkësive tona shoqërore. Arsimi i përhershëm së bashku me arsimin integral e demokratik do ta shndërrojë edukimin formal në shkollë moderne në të cilin të mësuarit bëhet proces komunikues ku dominon ideja e lirisë, pluralizmi, toleranca dhe individualiteti i nxënësve. Rexhepagiq e vlerëson demokratizimin e arsimit si një mjet të fuqishëm kundër burokratizmit dhe diskriminimit në arsim, si dhe kundër botëkuptimit mbi arsimin autoritar, ide që e bëjnë autorin të ketë vlera të mëdha ideore dhe shkencore në fushën e pedagogjisë, si testament pararendës për një filozofi moderne arsimore. Ne kemi nevojë ta studiojmë veprën e Tij, ku gjendet e mishëruar energjia, imagjinata, gjenialiteti.

Fjalë çelës: Arsim, demokratizim, mirëqenie, toleranca, ardhmëri, pedagogji.

\section{JASHAR REXHEPAGIQ'S IDEAS FOR DEMOCRATIZATION OF EDUCATION IN KOSOVO.}

\begin{abstract}
Jashar Rexhepagiq remains one of the prominent pedagogues of Kosovo's with half a century of dedication. Even now that virtual activity has transformed Kosovar society into a great school for a learning society, Rexhepagiq's pedagogical ideas sound current.
\end{abstract}


Hajri Mandri

Rexhepagiq has left behind a valuable asset in the field of pedagogy. He remains a great idealistic educator who projected himself into the future. Authentic democracy, concrete and practical in education, are not considered empty words, but ideas, which are feasible, real and future of our social communities. Permanent education together with integral and democratic education will transform formal education into a modern school in where learning becomes a communicative process dominated by the idea of freedom, pluralism, tolerance and individuality of students. Rexhepagiq considers the democratization in education as a powerful tool, against bureaucracy and discrimination in education, as well as against the worldview on authoritarian education, ideas that make the author to have great ideological and scientific values in the field of pedagogy, as a testament precursor to the philosophy of modern education. We must to study his work, where we can find merciful energy ,imagination, geniality.

Key words: Eduacation, democratization, welfare, tolerance, future, pedagogy

\section{HYRJE}

Një trashëgimi e begatë e shkencës pedagogjike, shfaqet vepra madhore shkencore e akademikut të parë të Kosovës dhe përfaqësuesit të përmasave ballkanike dhe më gjerë, Jashar Rexhepagiq ${ }^{1}$. Autori trajton veçoritë më esenciale, të përbashkëta, progresive demokratike në veprimtarinë arsimore dhe edukative, si kërkesë që lidhet me parimet e demokratizimit. Për thelbin e pedagogjisë bashkëkohore autori shpreh në mënyrë konçize idenë se "çështja nuk është, në radhë të parë të dimë, por se si (duhet) të dimë " 2 Pasuria e një vendi me siguri që varet nga resurse natyrore, me të cilat ai vend disponon, por se si do të shfrytëzohet ajo pasuri, kjo varet prej nivelit arsimor të popullatës. Arsimi, si instrument i veçantë i demokracisë, ka për qëllim të përgatitë njeriun e ditur dhe të lirë. Ky qëllim parashkruhet në Deklaratën e Përgjithshme mbi të drejtat e njeriut. Rexhepagiq duke iu referuar Federiko Major, ${ }^{3}$ lidh në mënyrë direkte demokracinë me arsimin dhe kulturën duke argumentuar se vetëm në sistemin demokratik zhvillohet liria personale, barazia e plotë mes qytetarëve dhe sigurohet arsimi i suksesshëm dhe bashkëkohor, por edhe vetë demokracia është pasojë dhe fryt $\mathrm{i}$ arsimit dhe edukimit. Sipas Rexhepagiqit, në shkollat ku fëmijët diskutojnë dhe debatojnë, ku zgjedhin dhe ku zgjidhen, ku mendimi i tyre respektohet dhe fjala e tyre dëgjohet, atje ushtrohet praktikisht demokracia. Përparimi i shkencës i teknikës dhe i teknologjisë janë faktorë që arsimi të jetë më i plotë, më i përhapur, më i përsosur dhe sa më i përshtatshëm, e këto janë po ashtu elemente të rëndësishme të arsimit demokratik. Sipas pikpamjeve të Rexhepagiqit, demokratizimi i arsimit nuk mund të përparojë me dituri minimale, sepse 
IDETË E JASHAR REXHEPAGIQIT PËR DEMOKRATIZIMIN E ARSIMIT NË KOSOVË.

ky parim fondamental na obligon që secili person të zhvillojë njohuritë shkencore, kulturore, morale e shoqërore. Me pabarazi në arsim nënkuptojmë dallimet e thella racore, kombëtare, fetare, sociale, kulturore, gjuhësore dhe gjinore. Çdo formë e pabarazisë është drejtpërdrejt kundër demokratizimit në arsim. Secili sistem arsimor, deomos duhet t'i plotësojë kërkesat demokratike. Raportet demokratike dhe humane ndërmjet mësuesve-nxënësve-prindërve është e domosdoshme në një shkollë ku synojmë një edukim demokratik. Me demokratizim të arsimit kuptojmë luftën kundër sundimit kulturor, gjuhësor e të tjera, të kombit më të madh ndaj popujve të vegjël, sidomos ndaj pakicave.

\section{DEMOKRATIZIMI NË ARSIM - SI IMPERATIV I KOHËS.}

Rexhepagiq duke dënuar qëndrimet diskriminuese në arsim në vitet 1918-41, por edhe në vitet 90' të shek. 20, për pikpamjet regresive ndaj arsimit në Kosovë dhe në viset shqipfolëse në Ish Jugosllavi thekson se " shkollat nuk kanë qenë të lira dhe të zhvilluara në nivelin e duhur, posaçërisht në gjuhën shqipe. Gati që fare nuk mund të flitet, po në atë kohë, për frymën demokratike në arsim, kur dominonin dallime të thella sociale dhe kundërshtime të mëdha në shkolla ( mbyllja e shkollave shqipe, mosfinancimi i tyre nga organet shtetërore,etj”.). ${ }^{4}$ Në kuadrin e demokratizimit të arsimit, Rexhepagiq kërkonte të zbatohen disa parime themelore. Për secilin individ të sigurohet marrja e diturive të përgjithshme dhe profesionale. Gjithëpërfshirje në arsim dhe të mbështeten personat me kushte të vështira jetese. Shkollat në Kosovë, jo vetëm në qytete, por edhe ato fshatra, ka filluar demokratizimi i shoqërisë, zbatimi dhe realizimi i reformës demokratizuese, duke realizuar barazi në arsim dhe edukim. Pa arsim dhe pa kulturë nuk është e mundur të zhvillohet dhe të përparojë demokracia. Demokratizimi në arsimin në shkollat shqipe kërkon kapërcimin e pengesave dhe mendësive raciste. Ky parim është direkt kundër diskriminimeve në arsim, gjuhë dhe kulturë, kundër të lënit pas dore të edukimit dhe dhe të arsimit të pakicave kombëtare apo diskriminimeve etnike, si dhe qëndrimit negativ ndaj shkollimit dhe arsimit të popullatës fshatare, kundër mosshkollimit të vajzave dhe grave shqiptare. Rexhepagiq ishte për një arsim të mesëm të hapur për të gjithë nxënësit që kanë kryer shkollën fillore. Arsimi i lartë të jetë sa më i përshtatshëm për rininë. Parimi i demokratizimit, thekson Rexhepagiq, realizohet në bazë të solidaritetit në punën arsimore dhe duke siguruar shkollimin pa pagesë. Ndër idetë që lidhen me demokratizimin e sistemit arsimor të shkollave shqipe, Rexhepagiq mbronte me forcë dhe decentralizimin e mbështetjes financiare, materiale dhe të personelit mësimdhënës me qëllim që të dominojë barazia faktike e arsimit, në çdo vend dhe në çdo rajon. Autori vlerëson rolin e UNICEF-it për zhvillimin e shkollave shqipe në Kosovë. 
Hajri Mandri

Rexhepagiq ballafaqon kurdoherë me guxim dhe pa hezitim të drejtat që përmbajnë dokumentet ndërkombëtare për arsimin dhe realitetin konkret të arsimimit të shqiptarëve në Kosovë dhe viset e tjera me popullsi shqiptare. Bashkëpunimi ndërkombëtar është për autorin një problem kyç për arritje cilësore në arsim dhe përbën parimin themelor krahas parimit të demokratizimit në fushën e arsimit. Hapja ndaj arritjeve bashkëkohore ndërkombëtare dhe përvojave më të suksesshme, si dhe shkollimi i studentëve në vende të zhvilluara është faktor zhvillimi i arsimit tonë kombëtar. Të rinjtë gjithnjë e më shumë edukohen dhe bëhen të vetëdijshëm për dinjitetin dhe barazinë e të gjithë njerëzve, pa marrë parasysh racën, ngjyrën, prejardhjen etnike ose fenë dhe në frymën e respektimit të të drejtave themelore të njeriut dhe të drejtës së popujve për vetëvendosje. Arsimi është formë komunikimi, formë e bashkësisë njerëzore, formë integrimi kulturor e shkencor. Globalizmi çon drejt integrimeve të suksesshme europiane dhe ndërtimin e pedagogjisë bashkëkohore. Për shkak të ndryshimeve të mëdha në kulturë dhe në arsim të popullatës, shkollat bëjnë një punë të rëndësishme sepse shërbejnë si mjet bashkimi, bashkojnë njerëzit me ide të ndryshme, zvogëlojnë dhe eleminojnë fanatizmin, antisemitizmin dhe racizmin. Aktorët e punës pedagogjike, sidomos mësimdhënësit, duhet të njihen sa më mirë me përvojën e sistemeve të përsosura të vendeve të zhvilluara si Francë, Japoni, Suedi, SHBA etj. Një ide interesante që autori shtjellon në punimet e tij mbi pedagogjinë moderne është edhe aftësimi i nxënësve me edukatën dhe arsimin ndërkulturor që do të thotë arsim për jetën në bashkësinë multietnike dhe multikulturore. Edhe edukimi për multikulturalizëm përbën në vetvete reformë demokratizuese për shqiptarët në Kosovë, Maqedoni, Mal i Zi dhe vise të tjera me popullatë shqipfolëse. Autori vlerëson se arsimi multietnik dhe multikulturor është ndër pasuritë më të mëdha në jetën shpirtërore dhe në pedagogjinë ndërkombëtare. Duke trajtuar çështje të integrimit në arsim, Rexhepagiq thekson se konceptet mbi edukatën integruese janë të kohës së re, dhe pa dyshim, të lidhura me ndryshimet dhe lëvizjet për reformimin e shkollave dhe të arsimit popullor, jo vetëm në trevat shqiptare por edhe në vende të ndryshme evropiane. Këto reforma sidomos të shkollës shqipe, kishin për qëllim që këto institucione edukativo-arsimore të liroheshin nga intelektualizmi i tepërt, nga formalizmi në dituritë e nxënësve, nga ndikimi i madh i shkollës herbartiane, nga ndikimi i pedagogjisë së punës, nga ideologjizimi i edukatës dhe i arsimit, veçanërisht në periudhën e sistemit socialist, dhe nga njëanshmëri të tjera. Një problem tjetër lidhur me demokratizimin dhe reformimin e sistemit lidhet edhe me konceptin e të mësuarit të përhershëm. Në trevat tona, nënvizon autori, atje ku dominon gjuha shqipe, deri vonë nuk kemi pasur as shkolla të detyrueshme fillore në gjuhën amtare, atëherë mund të kuptohet pse te ne, me shekuj, mbretëronte analfabetizmi dhe prapambetja. Këto dukuri përqindja e njerëzve pa shkollë, pa dituri, edhe sot janë kundërshtarët më të mëdhenj të dijes, 
IDETË E JASHAR REXHEPAGIQIT PËR DEMOKRATIZIMIN E ARSIMIT NË KOSOVË.

të shkencës, të arsimit, të kulturës dhe të qytetërimit shqiptar, pra dhe të arsimit të përhershëm. ${ }^{5}$ Kur analizon sistemet arsimore, Rexhepagiq thekson se një sistem për të qenë sa më demokratik, unik dhe human në çdo vend, në veçanti në arsimin shqiptar, ku arsimohen të rinj a të rritur, duhet të jetë i përshtatshëm, pa pagesë dhe për të gjithë, pa marrë parasysh strukturën sociale, gjininë, përkatësinë fetare, etnike e dallimet e tjera. Në analizën që u bën sistemeve shkollore të shqiptarëve, dallimet ndërmjet shkollave dhe formave të arsimit kanë shumë pasoja, në esencë negative, sidomos në aspektin e ngritjes kulturore dhe të integritetit etnik shqiptar. Nxënësit e një paraleli do ta kishin të vështirë për të vazhduar shkollën duke kaluar nga gjimnazi i Prishtinës në Tetovë apo në Tiranë. Jo vetëm programet por edhe planet mësimore janë me dallime të dukshme ndërmjet shkollave në Kosovë, në Maqedoni, në Mal të Zi dhe në Shqipëri. Dallimet në këto shkolla vetvetiu janë pengesë kryesore për të pasur më shumë tekste të përbashkëta në të gjitha shkollat dhe për nevojat e të gjitha niveleve të arsimit. Për shkaqe pedagogjike, kombëtare, etike dhe shkencore, organizatorët e arsimit në këto treva duhet të kontribuojnë sa më shumë për integrimin dhe lidhjen organike të sistemeve tona arsimore. Shkolla duhet të na bashkojë sa më shumë, dhe jo të bëhet pengesë e jetës sonë të përbashkët, të na integrojë e jo t’i shërbejë ndarjes së një populli të një gjuhe dhe kulture të përbashkët. Ky integrim mbarëshqiptar kërkon një adaptim të përbashkët të sistemit arsimor në trevat shqiptare, një sistem të reformuar dhe të integruar maksimalisht. Këtu nuk është fjala që të lihen menjëanë dallimet rajonale që përbëjnë diversitetin kulturor si vlerë. Ndër idetë moderne dhe demokratizuese duhet të përmendim edhe trajtimin e çështjes së harmonizimit të arsimit në përputhje me nevojat e ekonomisë dhe përshtatjes sipas tregut të punës.

Dituria është e lidhur me pasurinë e njeriut por kahjet e tyre ndryshojnë. Pasuria zvogëlohet me harxhim, ndërsa dituria shumohet me ndarje. Duke folur për gjendjen e arsimit në Kosovë, në vitet 90' autori e përshkruan atë si një gjendje të vështirë, ku ka dallime të mëdha në zhvillimin ekonomik, ka varfëri, papunësi, krizë morali e shoqëruar edhe me represionin e regjimit të Beogradit ku u pakësua numri i nxënësve. Mehmet Aliu, për gjimnazin “Sami Frashëri" të Prishtinës në vitin 1991 liroi dy shtëpitë e veta me 19 dhoma, në mungesë të objektit shkollor. Ky akt dhe shumë të tjerë tregojnë etjen e popullit të Kosovës për arsim, liri dhe demokraci. Autori tërheq vëmendjen se në literaturën dhe shkencën shqiptare çështja e integrimit të fushave të jetës shpirtërore dhe të prodhimit material nuk është studiuar sa duhet. Shkollat tona në një perspektivë jo të largët, duhet të synojnë për realizimin e programeve të reja për planifikimin e punës mësimore dhe pedagogjike, përveç kualifikimin dhe plotësimin e mësuesve, pedagogëve, psikologëve, punonjësit social, mjekun, biblotekarin e shkollave etj. Në bazë të njohjes së arsimit në të kaluarën dhe të arsimit në kohën e tanishme 
Hajri Mandri

mund të parashikohet dhe të planifikohet edhe arsimi në të ardhmen, përmes një studimi real, objektiv, mbështetur në trendet, tendencat dhe drejtimet e arsimit në Kosovë. Kështu autori konribuonte në pedagogjinë futurologjike. Studimet pedagogjike janë një nevojë e brendshme e zhvillimeve arsimore pasi siç thotë Makarenko, "pedagogjia është më dialektikja nga të gjitha shkencat.". ${ }^{6}$

\section{IDETË PEDAGOGJIKO - PSIKOLOGJIKE, ETIKA DHE ELEMENTET E SHKEN- CAVE TË TJERA NË “PEND-NAMEN" E FERIDUDDIN ATTARIT}

Një refleksion psikopedagogjik me vlera të larta shkencore është zbërthimi që Rexhepagiq i bën veprës së mendimtarit persian Feriduddin Attar ${ }^{7}$, i lindur rreth vitit 1220. "Pend-nama" është burim i rëndësishëm që është krijuar para tetë shekujsh. Një hulumtim, analizë dhe sitezë skrupuloze dhe model i ballafaqimit të fakteve dhe argumenteve. Ky libër shkollor, i shkruar në formë letrare, është përdorur një kohë të gjatë edhe në këto hapësira. Autori i saj Feriduddin Attar i takon plejadës së krijuesve të shkëlqyeshëm klasikë persianë. Me këto dhe vepra të tjera janë zhvilluar forma të ndryshme të shprehjes poetike e autorët e tyre kanë merita të posaçme për letërsinë didaktike. Attar e çmon jashtëzakonisht procesin e të nxënit, “Diturinë, qoftë edhe e vogël, mos e nënçmo, sepse dituria, vlerë të madhe ka. Nuk mjafton vetëm dituria, por ajo duhet të lidhet me aftësitë intelektuale që përvetësohen me anë të arsyes (logjikës). ${ }^{7}$ Këtë ndërlidhje Attar e ka definuar kështu: Dituria pa mend është e keqe, biro, dituria është shpend, e mendja flatër, bir. Kush ka dituri e s'ka mend, rrugën e arsyes ai e humb (mbetet anësh) ${ }^{8}$. Për më tepër, më me rëndësi është të zhvillohen aftësitë mendore, dhe Attar thotë: Dije se mendja është më e vlershmja në botë. ${ }^{9}$ Attar jep këtu një varg këshillash mbresëshe dhe të paharrueshme për fëmijët sepse janë të fituara edhe në bazë të përvojave jetësore të njerëzve të tjerë. Attar rekomandon sidomos të zhvillohet te fëmijët ndjenja e shoqërimit, e mirëbërjes në vend të koprracisë, të zhvillohen ndjenja të këndshme dhe t'u flitet fëmijëve për të bukurën. Attar e çmon shumë sjelljen njerëzore, ai besonte në fuqinë e njohurisë njerëzore dhe të zhvillimit intelektual të personalitetit. Nga libri del qëndrimi i rëndësishëm teorik se Attar e njihte me themel psikologjinë e pasanikëve, të koprracëve, të varfanjakëve, i njihte cilësitë e njerëzve të talentuar, të hipokritëve e të shenjave të personave të kufizuar, e njihte psikologjinë e fëmijëve. Lypësin e përshkruan kështu: Kur në rrugë të njohurin tënd e takon, si era fluturo dhe përshëndete në kalim. ${ }^{10}$ Attar ka vëzhguar një kohë të gjatë sjelljen e lypësve, fatkëqinjve dhe të tjerëve, manifstimet e tyre të jashtme dhe mënyrat e reagimeve të tyre. Më vonë biheviorizmi (anglisht Behavoir -sjellje), shkolla psikologjike e krijuar në SHBA në fillim të shekullit XX (Torndaik, Votson etj.) mbi këtë do ta mbështesë doktrinën e vet psikologjike dhe do të ushtrojë ndikim të madh dhe në sferat 
IDETË E JASHAR REXHEPAGIQIT PËR DEMOKRATIZIMIN E ARSIMIT NË KOSOVË.

jashtë psikologjisë (p.sh. në edukatën). Një shembëlltyrë të ndikimit të shenjave të jashtme sipas Attarit: "Në fytyrën e bujarit është drita e qetësia." Attar i çmon njerëzit e ditur, që janë me "karakter të bukur" dhe të veshur modestë, dhe ua sheh për të madhe atyre që e tejçmojnë veten dhe e lavdërojnë veprën e vet. Aty-këtu mbështet edhe përcaktimet e këtilla: Edhe po të jesh shumë i dijshëm dhe i arsimuar, veten e quaj më të ulët se çdo i padijshëm. ${ }^{11}$ Janë të sakta vërejtjet e Attarit se njeriu nuk ngritet në kokë të vet dhe se ai vetë duhet $t^{\text {ec }}$ i njohë aftësitë e veta. ${ }^{12}$ Çdo njeri përparon gjatë jetës me ndihmën e “diturisë, mendjes dhe zgjuarësisë”, që të arrijë deri te njohuritë e vërteta dhe sa më të plota. Attar nisej nga jeta dhe e vëzhgonte sistematikisht sjelljen e njerëzve, të shtresave të ndryshme shoqërore dhe të profesioneve të ndryshme e të kualiteteve individuale. Mbi këtë bazë mbështet edukata dhe arsimi si aktivitete themelore pedagogjike. Pedagogjia vjen në shprehje edhe atëherë kur u drejtohet fëmijëve çka duhet të punojnë, si të sillen në situata të ndryshme, me kë të shoqërohen dhe prej kujt të ikin, p.sh. të jenë të kujdesshëm dhe të ruhen nga mashtruesit, të padijshmit (injorantët), njerëzit lakmi tarë etj. Ndikimin pedagogjik të Attarit e vërejmë edhe në fjalët e maksimat me të cilat u drejtohet njerëzve në "Librin këshillave"13 Arsimi dhe edukimi, sipas Attarit, nuk janë veprimtari e njëtrajtshme, por proces kompleks dhe prandaj fëmijës i rekomandohet që teci hapë sytë për mësime dhe $t^{\text {ec }} i$ pranojë me shpirt këshillat e mësuesit. ${ }^{13}$ Kjo do të thotë se edhe fëmija duhet të jetë pjesëmarrës aktiv në edukim. Në Pend Name, (në fq. 103-104) Attarin e quan Piri Murshid, që do të thotë mësues, prijës shpirtëror. Ndriçimi i së vërtetes nga e pavërteta, theksimi i rolit të diturisë e të urtësisë, madhërimi kuranor i autoritetit të shkencës e të fuqisë së gjykimit, theksimi i bëmirësisë (i veprimeve të mira), kritika e të padishëmve e krahas këtyre dënimi i njerëzve hipokritë, i koprracëve dhe i plangprishësve, theksimi i drejtësisë, janë vetëm disa përmbajtje që janë shtruar në mënyrë të ngjashme edhe në "Pend-name". Attar ishte kundër përdorimit të fjalëve e të shprehjeve të këqija e vulgare. Ai shkruan se fjala e keqe është si dru i shëmtuar. Një varg përcaktimesh të përbashkëta gjendet në domenin e etikës në "Pend-name”. Shpeshherë përdoren termat: "maruf”, që do të thotë "mirë" dhe "munker", që do të thotë “i pazakonshëm, keq. Këto shprehje i përdorte Attar duke përcaktuar psikologjinë e sjelljes te fëmijët. Libri i këshillave i Attarit edhe sot mund të jetë me interes që të shihet si shkruheshin dikur tekstet shkollore dhe doracakët dhe çka u rekomandohej fëmijëve dhe rinisë në ato libra e çka konsiderohej negative dhe e ndaluar. Do të ishte shkencërisht e arsyeshme dhe pedagogjikisht e nevojshme që edhe në kohën tonë të kemi tekste shkollore të fushës së edukimit, sikurse janë marrëdhëniet morale, psikologjia e njerëzve të profesioneve të ndryshme, bota dhe psikika e fëmijës, kufijtë dhe mundësitë e edukatës sot, etika e mësimdhënësve dhe e edukatorëve. 
Hajri Mandri

\section{Përfundime:}

\section{IDETË PEDAGOGJIKE TË JASHAR REXHEPAGIQIT MBETEN AKTUALE.}

Jashar Rexhepagoq mbetet një ndër pedagogët e shquar të Kosovës me përkushtim gjysëmshekullor. Edhe tani kur veprimtaria virtuale e ka shnërruar shoqërinë kosovare në një shkollë të madhe të një shoqërie që mëson, idete pedagogjike të Rexhepagiqit tingëllojnë aktuale. Rexhepagiq la pas një pasuri të vyer në fushën e pedagogjisë. Ai si një edukator idealist i madh e projektoi veten në të ardhmen. Demokracia autentike, konkrete dhe praktike në arsim, nuk konsiderohen fjalë boshe, por ide, që është e realizueshme, reale dhe ardhshmëri e bashkësive tona shoqërore. Arsimi i përhershëm së bashku me arsimin integral e demokratik do ta shndërrojë edukimin formal në shkollë moderne në të cilin të mësuarit bëhet proces komunikues ku dominon ideja e lirisë, pluralizmi, toleranca dhe individualiteti i nxënësve. Rexhepagiq e vlerëson demokratizimin e arsimit si një mjet të fuqishëm kundër burokratizmit dhe diskriminimit në arsim, si dhe kundër botëkuptimit mbi arsimin autoritar, ide që e bëjnë autorin të ketë vlera të mëdha ideore dhe shkencore në fushën e pedagogjisë si testament pararendës për një filozofi moderne arsimore. Ne kemi nevojë ta lexojmë dhe kuptojmë veprën e Tij, ku gjendet e mishëruar energjia, imagjinata, gjenialiteti. Për sfidat që kemi përpara objektivi i shoqërisë mbarëshqiptare është krijimi i një shoqërie që mëson, të përfshirë për drejtësi sociale dhe mirëqenie. Le të jetë një libër i hapur për të gjithë ne trashëgimia pedagogjike e shkruar nga idelogu i shquar Jashar Rexhepagiq.

\section{Refernca:}

1. Attar, Feriduddin: "Pend-Namen" (Këshilla pedagogjike), sipas referencave të J. Rexhepagiq. Harnidullah, Muhammed: Uvod u Islam, Sarajevë, 1989

2. Koliqi, Hajrulla : Jashar Rexhepagiqi, figurë e shquar e arsimit dhe e shkencës. Shtëpia botuese e Librit shkollor, Prishtinë 2009

3. Kurean ëasni, Zagreb, 1969.

4. Rexhepagiq, Jashar : Çështje fundamentale në pedagogjinë ndërkombëtare - Prishtinë, r... .

5. Major, Federiko (Sutra je uvek kasno, Beograd,1991.

6. Rexhepagiq, Jashar: Shkollat dhe arsimi në Kosovë prej fundit të shek. XVIII deri 
IDETË E JASHAR REXHEPAGIQIT PËR DEMOKRATIZIMIN E ARSIMIT NË KOSOVË.

më 1918 (Š́kolstvo i prosveta na Kosovu od kraja XVII I stoljeċa do 1918) - 1974.

7. Rexhepagiq, Jashar :Pikëpamjet pedagogjike të Hegelit (Pedagoški pogledi Hegela) -1980 .

8. Rexhepagiq, Jashar: Etika e arsimtarit sot - 1989.

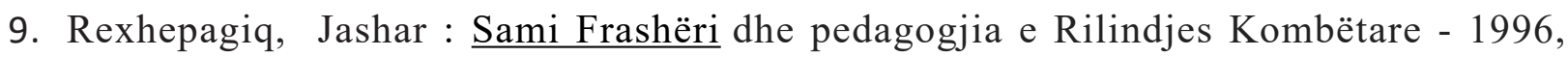
2005

10. Rexhepagiq Jashar: Kultura islamo-persiane dhe ndikimi i saj tek ne (Islamsko-persijska kultura i uticaj persijskog jezika u nas) - 1996.

11. Rexhepagiq, Jashar: Shkolla Normale “Sami Frashëri” në Prishtinë (1941-1944) 1997.

12. Rexhepagiq, Jashar: Refleksione pedagogjiko-letrare: Kontribut mbi arsimimin në Sanxhak (Pedagoško-literarne refleksije i odzivi:Prilog obrazovanju u Sandžaku) 1998.

13. Rexhepagiq, Jashar: Tema të zgjedhura dhe bashkëkohore pedeagogjike, Botim i Akademisë të shkencave dhe arteve të Kosovës, Prishtinë, 2002.

14. Koliqi, Hajrulla : Jashar Rexhepagiqi, figurë e shquar e arsimit dhe e shkencës. Shtëpia botuese e Librit shkollor, Prishtinë, 2009.

15. Major, Federiko : Sutra je uvek kasno, Beograd,1991. 